\title{
Clout Chasing for the Sake of Content Monetization: Gaming Algorithmic Architectures with Self- Moderation Strategies
}

Citation for published version (APA):

Costa Bertaglia, T., Dubois, A., \& Goanta, C. (2021). Clout Chasing for the Sake of Content Monetization: Gaming Algorithmic Architectures with Self-Moderation Strategies. Morals \& Machines, 1(1), 22-29. https://doi.org/10.5771/2747-5174-2021-1-22

Document status and date:

Published: 01/01/2021

DOI:

10.5771/2747-5174-2021-1-22

Document Version:

Publisher's PDF, also known as Version of record

Document license:

Taverne

Please check the document version of this publication:

- A submitted manuscript is the version of the article upon submission and before peer-review. There can be important differences between the submitted version and the official published version of record.

People interested in the research are advised to contact the author for the final version of the publication, or visit the DOI to the publisher's website.

- The final author version and the galley proof are versions of the publication after peer review.

- The final published version features the final layout of the paper including the volume, issue and page numbers.

Link to publication

\footnotetext{
General rights rights.

- You may freely distribute the URL identifying the publication in the public portal. please follow below link for the End User Agreement:

www.umlib.nl/taverne-license

Take down policy

If you believe that this document breaches copyright please contact us at:

repository@maastrichtuniversity.nl

providing details and we will investigate your claim.
}

Copyright and moral rights for the publications made accessible in the public portal are retained by the authors and/or other copyright owners and it is a condition of accessing publications that users recognise and abide by the legal requirements associated with these

- Users may download and print one copy of any publication from the public portal for the purpose of private study or research.

- You may not further distribute the material or use it for any profit-making activity or commercial gain

If the publication is distributed under the terms of Article $25 \mathrm{fa}$ of the Dutch Copyright Act, indicated by the "Taverne" license above, 


\section{Clout Chasing for the Sake of Content}

Monetization: Gaming

Algorithmic Architectures

with Self-Moderation

Strategies

AUTHORS: Thales Bertaglia, Adrien Dubois \& Catalina Goanta

KEYWORDS:

CONTENT CREATORS, ALGORITHMIC GOVERNANCE, SELF-MODERATION, CONTENT MONETIZATION

DOI:

https://doi.org/10.5771/2747-5174-2021-1-22 
Thales Bertaglia is a $\mathrm{PhD}$

candidate at the Institute

of Data Science and Studio

Europa (Maastricht University).

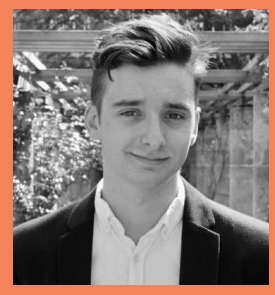

Adrien Dubois is a European

Law School student and member of the Influencer Law Clinic

(Maastricht University).

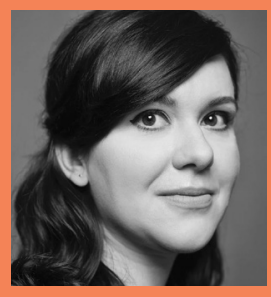

Catalina Goanta is an Assistant Professor in Private Law and \& Technology, and co-director of the Maastricht Law \& Tech Lab (Maastricht University).

\section{ABSTRACT:}

This short discussion paper addresses how controversy is monetized online by reflecting on a new iteration of the shock value in media production, identified on social media as the 'clout chasing' phenomenon. We first exemplify controversial behavior, and subsequently proceed to defining clout chasing, which we discuss this concept in relation to existing frameworks for the understanding of controversy on social media. We then outline what clout chasing entails as a content monetization strategy, and address the risks associated with this approach. In doing so, we introduce the concept of 'content self-moderation', which encompasses how creators use content moderation as a way to hedge monetization risks arising out of their reliance on controversy for economic growth. This concept is discussed in the context of the automated content governance entailed by algorithmic platform architectures, to contribute to existing scholarship on platform governance. 


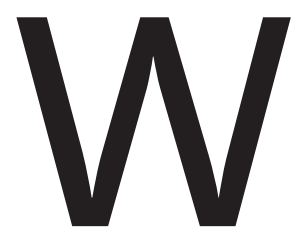

When we think about digital advertising, we imagine the Internet's traditional business model. Brands around the world pay digital platforms for ad space where they compete for user attention and engagement, an industry that can be referred to as platform ads. Brands register their ads in databases called 'ad archives' (Leerssen et al.2019) from where they can target selected platform demographics. These practices are enabled by the architecture of algorithmic platform systems that disseminate sponsored/ad content. Yet in the past decade, digital advertising has been generating new business models focused on the monetization of original and authentic content particularly on social media (Google 2014). Based on an increase in social media consumption, content monetization makes it profitable for Internet users to become producers rather than mere consumers of advertising. As such, this reflects new possibilities for Internet users to make money while democratizing media production. However, the control exercised by social media platforms on monetization broadens, as they become not only the algorithmic gatekeepers of content, but also of business opportunities.

Aseventhemarketingindustryacknowledges'advertisingisbecoming, well, less like advertising, due to the fact that the Internet has taken this industry into the 'age of authenticity' (O'Neil-Hart \& Blumenstein 2016). Influencer and affiliate marketing are illustrations of what content monetization looks like in advertising practice. Internet influencers, referred to as content creators in this piece, earn revenue from social media advertising by creating authentic, relatable content for their armies of followers. In turn, they receive money, goods or services (influencer marketing), or sales commissions (affiliate marketing). By hiring humans as ad banners, marketers and brands offer information(e.g.reviews)andexplorepersuasivenarratives(e.g.socialcauses) which audiences can relate to and engage with. The popularity of such advertising approaches is undeniable. In 2021 influencer marketing is projected to reach a global market size of $\$ 13.8$ billion $(700 \%$ increase since 2016), and affiliate marketing is estimated to grow to $\$ 7$ billion in the US alone (Statista 2021). Influencer marketing is by now so ubiquitous on social media, that it has become a synonym for content monetization, often used in a pejorative way, to criticize the willingness of content creators to sell their opinions (Atlantic 2019). This has also led to an increase in reports by popular news outlets that are slowly shedding light on social media practices and business models (New York Times 2019; Wired 2019; Forbes 2020).

Thebusinessofinfluenceisrapidlychanging.Ascontentmonetization shapes new business incentives on social media, speech is no longer a triangle involving the state, platforms and users (Balkin 2018). Content creators are an emerging category of stakeholders whose participation in content production turns engagement into currency in novel ways. They are caught between inconspicuous methods of monetizing user attention and safeguarding the relatable friend status perceived by their followers (O’Neil-Hart \& Blumenstein 2016).

In this ecosystem, capturing the attention of billions of users who scroll daily for entertainment content is no longer a measure of popularity and celebrity-level influence, but a direct reflection of monetization revenue. The fame and money cocktail has been attracting a growing number of aspiring amateur creators (e.g.micro-in- fluencers, with followers in the thousands or tens of thousands). At the same time, it consolidated the reach of creators who professionalized their activity while aggregating more viewer support (e.g. most followed influencers on given platforms). The resulting competition makes it more difficult for creators to stand out and start up, especially since the opacity of platform governance is perceived as a considerable hurdle to reputation growth. This is due to the discretion exercised by platforms in designing recommender architectures and applying sanctions to creators who do not comply with community guidelines (Caplan \& Gillespie 2020). A recent example of this discretion is one of the top 10 beauty YouTubers, James Charles. After allegations of inappropriate behavior towards minors came to light in early 2021, YouTube unilaterally decided to demonetize Charles (Lorenz \& Safronova 2021). In 2019, the influencer was also a prominent player in the Internet drama that led to the highest loss of subscribers ever registered on the platform for a content creator, when one of his friends and fellow influencers made a damning video accusing him of sexual harassment against minors (Lorenz 2019). At that time, he issued an apology video which was not well received by fans (Lorenz 2019). In consequence, the video was 'privated' (e.g. not publicly available anymore), and only a second, more popular video is currently still shown on the channel. Apology videos are generally not monetized, as that can be seen as controversial in itself (e.g. brands displayed in AdSense ad placements might not want to be in any way affiliated with Internet drama).

James Charles'example highlights two main issues. First, apart from making entertaining content, creators must gauge their likability not only towards fans, but most importantly, towards the platforms on which they are most active. This leads to creators strategizing their content around likeability as well as persuasion, whenever it is necessary to gain back or gain more reputational support. Second, when reputation is seriously affected in the public eye, creators are in jeopardy to be demonetized or deplatformed. To preserve the interests of their paying advertisers, platforms decide on a case by case basis whether to withdraw access to the platform and/or business opportunities from controversial influencers. When faced with legal standards, platforms often invoke the need for judicial action (e.g. a court order) for them 
to take action (e.g. share user details). However, in situations dealing with the deprecation of reputation, platforms monetize the notion of justice by using deprecating reputations to their favor.

Against this background, some creators still choose to rely on controversial behavior that captivates user attention based on shock value, and increases their algorithmic visibility through virality, or their monetization worth through increased engagement. This short discussion paper addresses how controversy is monetized by reflecting on a new iteration of the shock value in media production, identified on social media as the 'clout chasing' phenomenon. We first exemplify controversial behavior, and subsequently proceed to defining clout chasing, which we discuss this concept in relation to existing frameworks for the understanding of controversy on social media. We then outline what clout chasing entails as a content monetization strategy, and address the risks associated with this approach. In doing so, we introduce the concept of 'content self- moderation', which encompasses how creators use content moderation as a way to hedge monetization risks arising out of their reliance on controversy for economic growth.

\section{CONTROVERSY ON SOCIAL MEDIA: BEYOND LOGAN PAUL'S INFAMY}

How does controversy look like on social media? The example that has become somewhat of a synonym with controversy on Youtube is Logan Paul(Bishop2021),a Youtuberwhofilmedadead body in a Japanese so-called 'suicide forest' (Deller \& Murphy 2020). Yet controversy on social media reflects a much broader and perhaps more shocking array of activities which can be undertaken by creators to rise to Internet fame.

Lovely Peaches is probably one of the most controversial social media personalities of the moment (Mendez 2021). For the past five years, she has been engaging in what has been reported by mainstream media outlets as disturbing behavior. This behavior ranges from eating her own tampons and feces, to showing her genitals during live sessions held by popular underaged TikTok stars, or sharing stories about prostituting her infant daughter (Kozma 2021). Although it is unclear to what extent the self-reported criminal behavior (e.g. child abuse) is real, Internet users who stumbled upon her content felt they needed to take action by starting a petition to 'Investigate/Arrest Brittany Johnson aka Peaches aka @lovelypeaches4ever100' (Change.org 2019). The wave of consternation resulting from Peaches' controversial behavior even led to other users making designated Reddit threads such as $\mathrm{r} /$ lovelypeaches, to systematically record, interpret and discuss her actions (Reddit 2020). Some of the incidents generated by the content creator led to social media companies taking active measures to deplatform her by removing her accounts. This was, for instance, the case for Instagram, where Peaches lost an account that had gathered more than one million followers, after filming herself allegedly arranging for an underaged TikTok star, Charli D'Amelio, to be raped (Reddit 2020). In early 2021, Lovely Peaches is back on Instagram, albeit with a much more modest following: she alternates between two accounts totaling around 230k followers.

Another illustration of how controversy is embraced by content creators is TikTokker Danielle Cohn. Cohn rose to fame on Musically circa 2016 as a child, and through the guidance of her mother/ manager subsequently started shaping a risqué, sexualized personal brand in spite of being a young teenager (Harris 2020). Due to this, even her age has been the subject of debate, as Cohn is believed to initially have presented herself to her audience two year older than her real age. At around 13, Cohn was making clickbait videos on her Youtube channel, where she staged a wedding and a pregnancy (Harris 2020). Cohn currently has 18.3 million followers on TikTok, 4.7 million on Instagram, and 1.8 million subscribers on YouTube.

\section{CLOUT CHASING AND CONTENT MONETIZATION}

The illustrations discussed above show the choices some creators make to become or stay relevant in an entertainment and content production market that is increasingly defined by stiffer competition. This increased density of creators trying to make it on social media has affected the way in which some of them rely on marketing strategies to differentiate themselves and capture the attention of their audiences. Reliance on shocking content to gain fame is, however, nothing new, as sensationalism and shock value have long been ingredients for media popularity, with examples in this sense including television talk- shows such as Oprah (Illouz 1999) or Jerry Springer.

The newest iteration of shock value in media is called 'clout chasing. In common parlance, 'clout' is said to have a 'porous meaning, which ranges from 'power and influence' or 'digital cultural currency' to retweets or 'social capital' (Tiffany 2019). While evasive, the meaning of this term reflects the current content monetization ecosystem: the engagement that an audience creates over content will increase the revenue of a content creator in multiple ways. Firstly, by being more noticeable, a creator can reach a broader audience, and thus be a more valuable vessel for contractual endorsements or merchandising. Secondly, increased visibility generates revenue through the social media platform advertising policies themselves (e.g. Google AdSense revenue). Thus, clout chasing emerges out of the main goal of content creators, namely to arouse interaction from their audiences, which in turn increases their market standing. Engagement can be defined in a 
plethora of ways, such as 'the emotional, intuitive experiences or perceptions that people undergo when using a particular medium at a particular moment' (Voorveld et al. 2018). These experiences are delivered by fully automated architectures that generally rely on recommender systems, and are operationalized into platform affordances such as the measurement of impressions, the possibility to react to posts, to leave comments, and even to share the content beyond one given platform. For instance, links from TikTok have unique identifiers, so that when they are shared on other platforms (e.g. WhatsApp, whose icon is even used on the TikTok app as a 'share' button), they can be traced, allowing TikTok to know exactly how and where and from whom users get redirected to the platform.

Some content creators do not hesitate to artificially stimulate audience engagement by deliberately producing controversial content to attract as much attention as possible - which has been the case for both Lovely Peaches and Danielle Cohn. Controversy itself is a fluid concept with a plethora of meanings, but social scientists have defined it by referring to scandal, debate, dispute or polarization (Marres \& Moats 2015). More specifically, controversy entails the polarization of a social process into two opposing subgroups having conflicting and contrasting positions, goals, and views (Qiu, 2019), or a process whereby participants to an online discussion develop 'arguments and conflicting views that lead them to offer different versions of the social and the natural world' (Callon 1986; Smyrnaios \& Ratinaud 2017), which can be evaluated by the amount of discussion it generates (Coletto 2017). In content creation, controversies reflect a considerable amount of speculation regarding what could antagonize audiences in such ways that intense conflicts can lead to more views, comments or even dislikes. From this perspective, clout chasing has an intentional dimension targeted at emotionally triggering reactions out of viewers. Those emotions may be the result of the shock reflected by the perceived violation of public values or morals.

On social media, controversies appear in two ways. Firstly, the subject of the content itself can be controversial. Subjects that are not widely accepted or that require a subjective position such as political opinions or topics closely linked to public morals can be the initial point of controversy. Clout chasing occurs when creators do not only want to create debates in their communities, but have the intention to shock and thus trigger strong emotions with the subject of such debates. A very good example of this first angle into controversy appearance is reflected by conspiracy videos. Given their popularity, conspiracy theories attract considerable amounts of views. Even though they may not come across as fully believing in conspiracies, creators may use conspiracies to stimulate their view counts (Harper 2021). Similarly, Lovely Peaches creates content that may be deemed inappropriate for certain audiences (e.g. sexual intercourse videos). Secondly, the manner in which the content is presented can be controversial. In order to increase the level of engagement, influencers do not hesitate to use doubtful marketing techniques. Examples include using photoshopped thumbnails alluding to content of a different nature than the one presented, clickbait titles or sexualized content, as reflected by Danielle Cohn's YouTube channel (Politifact 2017). The wide-spread adoption of clout chasing as an aspirational entrepreneurial attitude on social media raises concerns regarding the negative impact it may have on the business ecosystem but also on the very users themselves. The tension resulting from controversies often leads to aggressive exchanges (e.g. hate speech) and a feeling of diminishment of the opponent in the public debate. It has been illustrated numerous times that social media leads to though radicalization (Spohr, 2017). Furthermore, the quest for content creators to differentiate themselves through controversies leads to a vicious circle: audiences that are more used to controversies become insensitive, requiring a stronger trigger of their emotions. Perhaps most importantly, content creators engage in a relationship of trust with their community of followers, due to their relatable and authentic nature. The use of a community's reactions to stimulate engagement can be considered as a conflict of interest. The increased influence of content creators on their audience, combined with controversial topics is a dangerous cocktail (Taylor, 2020), as was shown by the \#icrecreamchallenge public health hazard. This viral challenge led to multiple arrests in the US after youngsters embraced a social media challenge consisting of recording themselves licking ice cream from a tub and putting it back on a supermarket's freezer shelf (BBC 2019).

\section{CONTENT SELF-MODERATION AS RISK AVOIDANCE}

Controversial influencer behavior may increase visibility and engagement, but at the same time, it may also put creators at risk towards platforms and potential brand partners, depending on what business models they employ. According to a recent taxonomy of monetization models (De Gregorio \& Goanta), creators generally have the following options to monetizecontent:

\footnotetext{
- Revenue from brands (influencer/affiliate marketing): brands offer money, goods, services or sales in exchange for the creation of native advertising by influencers (Goanta \& Wildhaber 2019).

- Revenue from platforms: creators rely on mediated revenue paid by platforms such as ad revenue (creators can place platform ads on their channel; Caplan \& Gillespie 2020; Bishop 2020), channel subscription (users can subscribe to premium content from creators; Huotari \& Ritala 2021), tokens (users can purchase alternative 'currencies' to spend on specific types of content from favourite creators, e.g. during live streams; Goanta \& Ranchordás
} 
2020), or crowdfunding (users can become the patrons of their preferred creators; Sokolova \& Perez 2017).

- Unmediated revenue from peers: Creators can also be supported by their peers more directly, through decentralized technologies.

An example of an infrastructure which is starting to gain traction

in this respect is the Web Monetization protocol, a payment standard which allows creators to receive microtransactions from their supporters without any platform acting as an intermediary (Goanta 2021).

- Direct selling: Creators can also choose to create and sell their own products

(e.g. 'merch').

Social media platforms are moving towards more advertiser-friendly and brand-safe content guidelines (Bishop 2021), aimed to scale back the level of controversy embraced by content creators. Youtube's own guidelines to this end are available for its AdSense programme (Google 2021). This may lead to the exercise of discretion in applying sanctions for creatingcontentthatgoesagainsttheseguidelines (Caplan \& Gilespie). Creators may still monetize their content outside of platform ads, namely by relying on external sponsors and affiliate programmes. One of Lovely Peaches' Instagram accounts includes an affiliate link to a reward website promising Amazon gift cards worth $\$ 1000$ for the completion of a survey/ contest. Such a business model is recognized by the United States Better Business Bureau (BBB) as a scam focused on obtaining consumer personal data (BBB 2021). This raises the point that even extremely controversial content is monetizable, although it is practically impossible to estimate how difficult it would be to obtain sustainable revenue in this context without further private transactional insights. Similarly, Danielle Cohn's controversialcontent did not make her sponsors shy away, and she is currently known to have quite considerable brand deals with retail companies (e.g. Fashion Nova) or energy drinks (e.g. Bang Energy). Especially in "relation to the latter, the very transactional relationship may be prone to controversy. Energy drinks but also sugar-rich soft drinks in general are considered to be dangerous for the health of children, so a young teenager being a brand ambassador may even raise questions of compliance with health and safety public rules which ought to be taken into account in the process of content modera- tion. Faced with a wide array of possibilities for content monetization, controversial creators must navigate between three main stakeholders: platforms, brands and viewers (not just followers but also other users who stay updated on a controversial creator's content). Two main points need to be addressed here. First, as they have a contractual relationship with platforms that can be at any times unilaterally severed, controversial creators must find a balance between more and less risky content. In Peaches' case, this entails constantly posting and deleting photos and videos on Instagram. Second, the attention of brands and viewers must also be treaded on carefully: polarizing opinions may be beneficial to creators if they manage to maintain a balance between the groups of fans and non-fans. Loosing too much support can lead to decreased engagement between polarizing groups, which in turn can make a creator less popular and thus less desirable to engage in brand deals.

To achieve this balance, creators heavily rely on self-moderation. This process entails editorial control over produced content which shows the effects of controversial content production. For instance, when creator controversy escalates to a point where a public apology is due, creators post apology videos in the hope of calming the waters. Yet depending on how these videos are perceived, they may be shortly deleted by their makers (Haylock 2020), and even replaced on the basis of adapted strategies of hedging further reputation loss or controversy risk. This reflects a dynamic approach to creator brand management, whereby public perception may trigger content moderation reactions from creators. The automated nature of the architectures creators must engage with for monetization purposes raises a lot of information and business literacy issues. Given its opacity, automated content governance leads to very subjective avoidance techniques, based on e.g. the 'theorizations of algorithmic visibility' by algorithmic ' experts' (Bishop 2020), or by experimental brand management, whereby creators try to build and save persuasive reputations, sometimes with the help of other participants in the monetization supply chain, such as content management platforms (Bishop 2021). On the one hand, such techniques of adapting to techno-social systems in ways that can be commercially beneficial showcase a high degree of creativity and business acumen; on the other hand, by developing gaming strategies against algorithmic content moderation and governance, creators are said to be 'complicit with YouTube's organizational strategies and business models' (Bishop2020).Traditionally,platform governancehas played acentral role in the discussion of creator management (Cunningham \& Craig 2019). However, as the landscape of content monetization in 2021 shows, professional creators pivot between an increasing number of platforms that help them spread platform governance risks (Goanta 2021). Moreover, especially in the case of controversial creators, they seem to play an increasingly active role in the moderation of own content. At the same time, self- moderation can also be further expanded to cover content strategies that take into account platform affordances, depending, among others, on the additional stakeholders involved in the content monetization supply chain (e.g. talent companies). Additional research can build on the concept of self-moderation to complement existing platform governance narratives with a perspective over how social media platform and monetization plurality can enhance the agency and individual power of content creators. 


\section{REFERENCES:}

Balkin, J. (2018). Speech is a Triangle. Columbia Law Review, 118(7) https://columbialawreview.org/content/ free-speech-is-a-triangle/

BBC News. (2019, July 8). Ice cream licker in Texas whips up a storm.

https://www.bbc.com/news/world-us-

canada-48910226

Better Business Bureau. (2021). Reward Zone USA. https://www.bbb.org/us/ny/new-york/profile/marketingprograms/reward-zone-usa-llc-0121-141760/complaints

Bishop, S. (2020). Algorithmic Experts: Selling Algorithmic Lore on YouTube. Social Media + Society, 6(1). https://doi.org/10.1177/2056305119897323

Bishop, S. (2021). Influencer

Management Tools: Algorithmic Cultures, Brand Safety, and Bias. Social Media + Society. https://doi. org/10.1177/20563051211003066

Callon, M. (1986). Éléments pour une sociologie de la traduction. La domestication des coquilles SaintJacques et des marins-pêcheurs dans la baie de SaintBrieuc. Lannée sociologique, 36, 169-208.

Caplan, R., \& Gillespie, T. (2020). Tiered Governance and Demonetization: The Shifting Terms of Labor and Compensation in the Platform Economy. Social Media + Society, 6(2). https://doi. org/10.1177/2056305120936636

Charles R. Taylor (2020, November 9). The urgent need for more research on influencer marketing. International Journal of Advertising. https://doi.org/10.1080/0265 0487.2020.1822104

Coletto, M., Garimella, K., Gionis, A., \& Lucchese, C. (2017). Automatic controversy detection in social media: A content-independent motif-based approach. Online Social Networks and Media, 3-4(Supplement C). https://doi.org/10.1016/j.osnem.2017.10.001

Cunningham, S., \& Craig, D. (2019). Creator Governance in Social Media Entertainment. Social Media + Society. https://doi.org/10.1177/2056305119883428 De Gregorio, G., \& Goanta, C. (November 4, 2020) The Influencer Republic: Monetizing Political Speech on Social Media. Available at SSRN: https://ssrn.com/ abstract=3725188

Deller, R. A., \& Murphy, K. (2020). 'Zoella hasn't really written a book, she's written a cheque': Mainstream media representations of YouTube celebrities. European Journal of Cultural Studies, 23(1),112-132. https://doi. org/10.1177/1367549419861638

Gillin, J. (2017). PolitiFact - The more outrageous, the better: How clickbait ads make money for fake news sites. Politifact. https://www.politifact.com/article/2017/ oct/04/more-outrageous-better-how-clickbait-ads-makemone/
Goanta, C. (2021, March 29). Monetizing philanthropy: First findings. Web Monetization Community. https:// community.webmonetization.org/philanthropy/monetizing-philanthropy-first-findings-3m $4 \mathrm{~b}$

Goanta, C. \& Ranchordás, S. (2020).

The Regulation of Social Media

nfluencers. Edward Elgar.

Goanta, C. \& Wildhaber, I. (2019). In the Business of Influence: Contractual Practices and Social Media Content Monetisation. Swiss Review of Business and Financial Market Law, 4, 346-357.

Google. (2021). Advertiser-friendly content guidelines - YouTube Help. https://support.google.com/youtube/ answer/6162278?hl=en

Harper, J. (2021). How to make money with fake news. Deutsche Welle. https://www.dw.com/en/theconspiracy-business-how-to-make-money-with-fakenews/a-56660466

Harris, M. (2020, August 19). Teen influencer Danielle Cohn reignited speculation about her real age when she suggested she was 14 on Instagram. Here's how the social media star rose to prominence online. Insider. https://www.insider.com/danielle-cohn-age-youtube-instagram-tiktok-drama-teen-bio-instagram-2020-7

Haylock, Z. (2020, December 17). The Best, Fakest, and Most Teary Influencer Apologies of 2020. Vulture. https://www.vulture.com/2020/12/influencer-apologies2020-shane-dawson-jenna-marbles.html

Voorveld H.A.M., van Noort, G., Muntinga D. G. \& Bronner, F. (2018). Engagement with Social Media and Social Media Advertising: The Differentiating Role of Platform Type, Journal of Advertising, 47:1,38-54, DOI: 10.1080/00913367.2017.1405754

Huotari, P. \& Ritala, P. (2021). When to switch between subscription-based and ad-sponsored business models: Strategic implications of decreasing content novelty. Journal of Business Research, 129, 14-28.

Illouz, E. (1999) “'That Shadowy Realm of the Interior: Oprah Winfrey and Hamlet's Glass". International Journal of Cultural Studies. https://doi. org/10.1177/136787799900200106

Kiran, G. Gianmarco De Francisci M. Aristides, G. Michael, M. (February 2018) Quantifying Controversy on Social Media. Trans. Soc. Comput. https://doi. org $/ 10.1145 / 3140565$

Kozma, L. (2021, February 24). What Did Lovely Peaches Do to Her Daughter (Proceed With Caution!). Distractify. https://www.distractify.com/p/what-did-lovely-peaches-do-to-her-daughter

Leerssen, P. \& Ausloos, J. \& Zarouali, B. \& Helberger N. \& de Vreese, C. H. (2019). Platform ad archives: promises and pitfalls. Internet Policy Review, 8(4). https:// doi.org/10.14763/2019.4.1421
Lorenz, T., \& Safronova, V. (2021, April 21). Why James Charles has been demonetized by youtube. The New York Times. https://www.nytimes.com/2021/04/21/style/james-charles-youtube-demonetized.html

Lorenz, T. (2019, May 16). How tea accounts are fueling influencer feuds. The Atlantic. https:/www.theatlantic. com/technology/archive/2019/05/how-tea-channelsfeed-youtube-feuds/589618/

Marres, N., \& Moats, D. (2015). Mapping Controversies with Social Media: The Case for Symmetry. Social Media + Society. https://doi. org/10.1177/2056305115604176

Martineau, P. (2019, December 4). What's an Influencer? The Complete WIRED Guide. Wired. https://www. wired.com/story/what-is-an-influencer/

Mendez, M. (2021, January 27). Controversial Instagram star Lovely Peaches arrested on animal-cruelty charge

after claiming she broke her dog's legs. Insider. https:// www.insider.com/lovely-peaches-arrest-instagram-video-dogalleged-animal-cruelty-2021-1

Qiu, J., Lin, Z., \& Shuai, Q. (2019).

Investigating the opinions distribution in the controversy on social media. Inf. Sci. https://doi.org/10.1016/j. ins.2019.03.041

Roose, K. (16 July 2019). Don’t Scoff at Influencers. They're taking over the World. New York Times. https://www.nytimes.com/2019/07/16/technology/vidcon-social-media-influencers.html.

Sign the Petition. (2019). Change.Org. https://www. change.org/p/police-department-investigate-arrest-brittany-johnson-aka-peaches-aka-lovelypeaches 4 ever100

Smyrnaios, N., \& Ratinaud, P. (2017). The Charlie Hebdo Attacks on Twitter: A Comparative Analysis of a Political Controversy in English and French. Social Media + Society. https://doi.org/10.1177/2056305117693647

Sokolova, K. \& Perez, C. (2017). The Impact of Social Media on Leetchi Crowdfunding Projects Success. Proceedings of the 2017 IEEE/ACM International Conference on Advances in Social Networks Analysis and Mining 2017 (ASONAM ,17).

Spohr, D. (2017, August 23) Fake news and ideological polarization: Filter bubbles and selective exposure on social media. Business Information Review. https://doi. org/10.1177/0266382117722446

Statista. (2021, February 12). Global influencer marketing value 2016-2021. https://www.statista.com/statistics/1092819/global-influencer-market-size/

Suciu, P. (2020, February 14). Is Being A Social Media Influencer A Real Career? Forbes. https://www.forbes. com/sites/petersuciu/2020/02/14/is-being-a-social-media-influencer-a-real-career/ 
ThinkwithGoogle. (2014, September 3). Blurred Lines Between Branded Video Content and Ads. Think with Google. https:/www.thinkwithgoogle.com/marketingstrategies/video/youtube-insights-stats-data-trends-vol8/

Tiffany, K. (2019, December 23). What Does Clout Mean? The Atlantic. https://www.theatlantic.com/ technology/archive/2019/12/clout-definition-meme-influencers-social-capital-youtube/603895/

Who is Lovely Peaches? A brief

introduction. (2020, October 12). Reddit. https://www. reddit.com/r/lovelypeaches/comments/j9h0h5/who_is_ lovely_peaches_a_brief_introduction/ 